\title{
N-Terminal Pro-BNP in Acute Coronary Syndrome Patients with ST Elevation versus Non ST Elevation Myocardial Infarction
}

\author{
Ragaa H. M. Salama ${ }^{1 *}$, Alaa E. A. El-Moniem², Nour El-Hefney², Tarek Samor ${ }^{3}$ \\ Department of ${ }^{1}$ Biochemistry; ${ }^{2}$ Medicine, College of Medicine, Qassim University, Qassim, Kingdom of Saudi Arabia; ${ }^{3}$ Consultant \\ of Coronary Care Unite, King Fahed Specialist Hospital, Kingdom of Saudi Arabia. \\ Email: *ragaa_2002@yahoo.com
}

Received August $25^{\text {th }}, 2010$; revised January $11^{\text {th }}, 2011$; accepted January $28^{\text {th }}, 2011$.

\begin{abstract}
The study aimed to evaluate the differences in secretion of NT-proBNP and conventional cardiac markers in patients with STE-ACS vs NSTE-ACS as a trial to solve the dilemma of the early detection of myocardial ischemia in NSTE-ACS. Sixty two patients with acute coronary syndrome (ACS) divided into 2 groups according to ECG: group 1 with elevated ST segment in ECG (STE-ACS) and group 2 with non elevated ST segment (NSTE-ACS). Twenty healthy subjects with matched age and sex were enrolled as control group in this study. In the sera of all subjects, levels of NT-proBNP, $C K-M B$ and troponin-T were measured by different kits. CK-MB and TnT were both significantly higher in STE-ACS patients compared to NSTE-ACS patients. Conversely, NT-proBNP was significantly higher in NSTE-ACS patients than STE-ACS especially within 4 hours from onset of chest pain. Comparison between NT-proBNP, TnT and CK-MB levels by $R O C$ curves revealed area under the curves $=0.68,0.31,0.17$ respectively. NT-proBNP at cutoff $415 \mathrm{pg} / \mathrm{mL}$ in NSTE-ACS patients had higher sensitivity and specificity (92\%, 39\%; respectively) than other markers that will help in early diagnosis of NSTE-ACS.
\end{abstract}

Keywords: NT-proPNB, Acute Coronary Syndrome, ST Segment, Cardiac Markers

\section{Introduction}

The serum level of N-terminal B-type natriuretic peptide (NT-proBNP) was elevated in patients with left ventricular (LV) dysfunction and showed a close correlation with the BNP level. Many reports declared that the absolute increment of NT-proBNP exceeded that of BNP, and that NT-proBNP would be a more discerning marker for the detection and evaluation of cardiac dysfunction than BNP [1]. B-type natriuretic peptide (BNP) and NT-proBNP can help to identify and accurately discriminated CHF from respiratory disease and non-cardiac causes of acute dyspnea [2,3]. NT-proBNP measurement act as a guide to current treatment strategies, as well as novel strategies, in patients with acute myocardial infarction and as markers for the severity of heart failure $[4,5]$. NT-proBNP provided information that may be superior to clinical judgment for the diagnostic evaluation of the patient with possible HF. It was a surrogate biomarker for prognosis of myocardial damage as assessed by contrast-enhanced Cardiac MRI [6]. It was an independent predictor of survival in patients with hypertension and increased left ventricular mass [7]. CK-MB was a marker of cytosolic damage that reflected the area at risk and the resultant size of the infarction. Whereas Tn-T was a marker of myofibril damage and elevated in proportion to infarct size per se. The clinical spectrum of ACS consists of ST elevated (STE) myocardial infarction (MI) (STEMI) and non-STE (NSTE) MI (NSTEMI)/or unstable angina (UA), which are classified from the acute phase electrocardiography (ECG) changes and the development of myocardial necrosis. STEMI caused by acute total coronary occlusion, whereas NSTEMI associated with vulnerable plaque and subocclusive thrombosis [8].

This study aimed to evaluate the clinical utility NT-proBNP in Saudi patients and early detection of myocardial ischemia in NSTE-ACS and the best time for treatment of the disease by synthetic peptide molecule.

\section{Materials and Methods}

This is a prospective case control hospital based study 
included 62 selected patients with acute chest pain or dyspnea. The informed consent was obtained from every patient. Those patients diagnosed as ACS according to Braunwald's classification [9], or acute MI (AMI) according to the redefined ESC/ACC Committee criteria were admitted to Coronary Care Unit (CCU), King Fahed Spealist Hospital in the duration from January to June 2009. Fifty four of them were males and 8 were females with ages ranged 27 - 65 years. All patients presented to CCU within 10 hours from onset of chest pain. Also, 20 healthy subjects served as control group with matched age and sex. The patients had cardiopulmonary resuscitation before admission, serum creatinine level > $2.0 \mathrm{mg} / \mathrm{dl}$, overt pump failure ( $\geq$ NYHA class II) or hypertension were excluded, in order to focus on the effect of myocardial ischemia per se on the release of NT-pro-BNP. All patients subjected to standard 12-lead ECG immediately after admission. The patients were classified into STE and NSTE groups based on the ECG findings on admission. Patients with ST segment elevation at the $\mathrm{J}$ point in 2 or more consecutive leads (with the cut-off point being $>0.2 \mathrm{mV}$ in leads V1, V2, or V3, and $>0.1 \mathrm{mV}$ in the other leads) were defined as having STE-ACS while patients with ST segment depression, T wave inversion, or no ECG abnormalities were defined as having NSTE-ACS, 17 of them diagnosed as unstable angina. Transthoracic 2-dimensional echocardiography was performed within $24 \mathrm{~h}$ of admission. The LV end-diastolic (LVEDD) and left ventricular end-systolic diameters (LVESD) were measured according to the guidelines of the American Society of Echocardiography [10]. The LV ejection fraction (LVEF) was calculated by the modified Simpson's method. Coronary angiography was done for determination of the affected vessel. The study was approved by the ethical committee of Kingdom of Saudi Arabia, Qassium province, Ministry of Health.

Blood samples were taken from every patient immediately after admission, centrifuged for $20 \mathrm{~min}$ at 2000 $\mathrm{xg}$ on $4^{\circ} \mathrm{C}$, and sera were separated divided into aliquots, kept at $-70^{\circ} \mathrm{C}$ for biochemical measurements of CK-MB, TnT and NT-proBNP.

Serum CK-MB levels measured kinetically by UV method (Stein and Bohner, 1985). Serum level of Tn-T measured by an electrochemiluminescence assay (Elecsys 2010, Roche Diagnostics Germany). NT-proBNP was measured by using sandwich enzyme immunoassay kit for the quantitative determination of $\mathrm{N}$-terminal proBNP human in serum from Alpco diagnostics ${ }^{\mathrm{TM}}$ USA. Catalog \# (SK-1204 BNP fragment EIA).

\section{Statistical Analysis}

SPSS version 16 was used in analysis of the data. The cardiac markers expressed as mean \pm standard error. The NSTE-ACS and STE-ACS groups compared by the Mann-Whitney $U$ test. While ANOVA test used to compare between different cardiac markers. Correlation coefficient calculated to asses the relation between NT-proBNP and CK-MB, TnT. Differences of percentages were compared by the chi-square test. ROC curves done and area under the curves determined. The cardiac markers and NT-proBNP levels on admission were grouped according to the time from onset of chest pain to admission of hospital, and the values compared between NSTE-ACS and STE-ACS patients by independent $\mathrm{T}$-test at cut point 4 hours, 6 hours and 8 hours to detect the peck point of secretion of NT-proBNP. A $p$-value equal or less than 0.05 was considered statistically significant.

\section{Results}

The data of all patients (62) with acute coronary syndrome (ACS) were shown in Table 1. The number of STE-ACS was 36 while NSTE-ACS was 26 patients. There was no statistical significant difference in age, $\mathrm{DM}$, smokers, previous MI, hyperlipidemia, $\mathrm{EF} \%$ or angiography between STE-ACS and NSTE-ACS. However, the female was significantly increased in STE-ACS while smokers are higher in STE-ACS but, didn't reach significant level. NT-proBNP level on admission was significantly higher in the NSTE-ACS compared to STE-ACS as shown in Figure 1. However, the conventional cardiac markers (CK-MB and Tn-T) levels on admission were significantly higher in STE-ACS patients than NSTE-ACS as shown in Figures 2, 3 respectively and Table 2 .

Table 1. Baseline characteristics of the patients with acute coronary syndrome (ACS).

\begin{tabular}{lcc}
\hline & $\begin{array}{c}\text { STE-ACS } \\
(n=36)\end{array}$ & $\begin{array}{c}\text { NSTE-ACS } \\
(n=26)\end{array}$ \\
\hline Age, years & $60.72 \pm 0.9$ & $62.38 \pm 0.8$ \\
Male/female & $28 / 8$ & $26 / 0 \%$ \\
Smoking $n(\%)$ & $20(55.5 \%)$ & $10(38 \%)$ \\
DM, $n(\%)$ & $20(55.5 \%)$ & $12(46.1 \%)$ \\
Hyperlipidemia, $n(\%)$ & $28(77.7 \%)$ & $18(69.2 \%)$ \\
Previous MI, $n(\%)$ & $12(33.3 \%)$ & $12(46.15)$ \\
EF\% & $(57.1 \% \pm 9.8 \%)$ & $(56.6 \% \pm 10.9 \%)$ \\
Coronary angiography: & & \\
One vessels disease & $24(66.7 \%)$ & $16(61.5 \%)$ \\
Two vessels disease & $8(22.2 \%)$ & $8(30.7 \%)$ \\
Three vessels disease & $4(11.1 \%)$ & $2(7.8 \%)$ \\
\hline
\end{tabular}

STE-ACS, ST elevation acute coronary syndrome; NSTE-ACS, non-ST elevation acute coronary syndrome; $\mathrm{EF} \%$, ejection fraction; $\mathrm{MI}$, myocardial infarction. " statistically significance, $p<0.05$ by chi square test. 


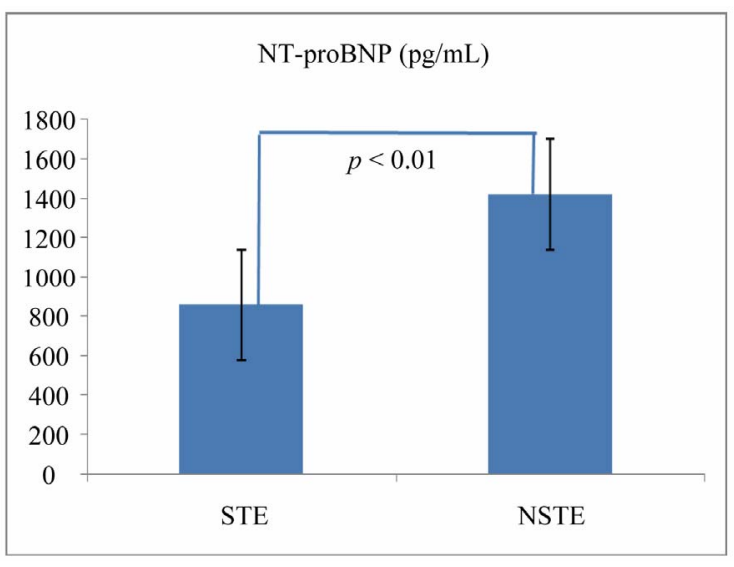

Figure 1. NT-proBNP in STE-ACS and NST-ACS.

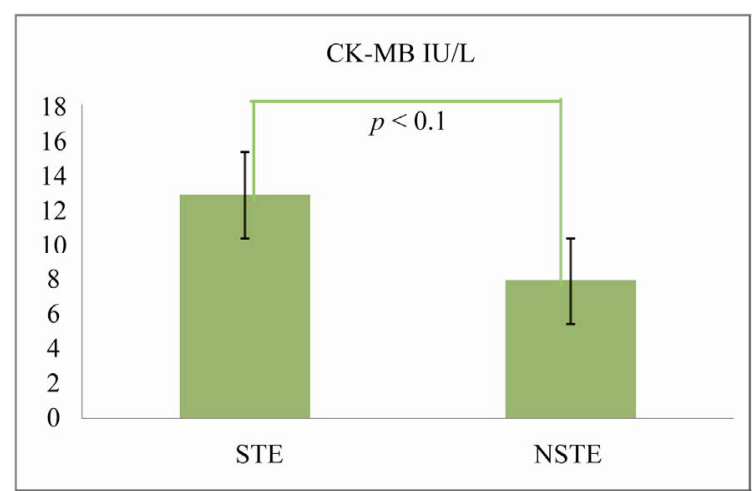

Figure 2. CK-MB in STE-ACS and NST-ACS.

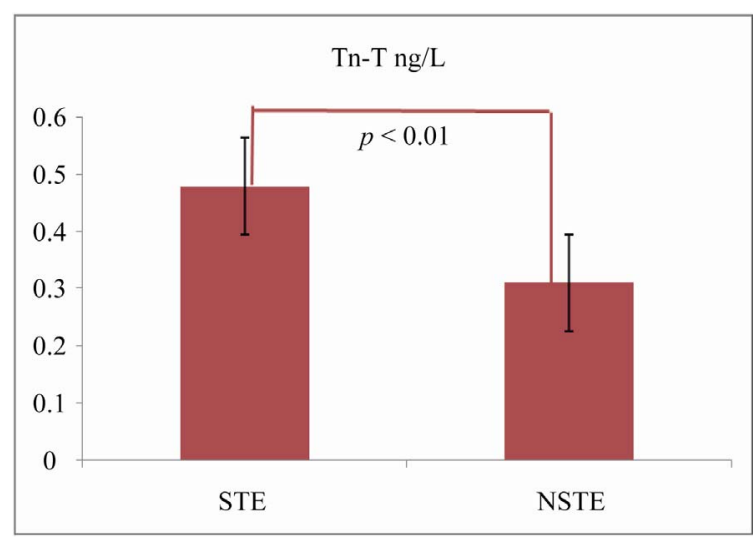

Figure 3. Tn-T in STE-ACS and NST-ACS.
In Figure 4, ROC curves of STE-ACS patients showed that $\mathrm{CK}-\mathrm{MB}$ had higher sensitivity and specificity, followed by Tn-T then NT-proBNP (cut-off $=415$ $\mathrm{pg} / \mathrm{mL}, 61 \%, 8 \%$, respectively). The area under the curve was $0.82,0.69,0.32$, respectively. On the other hand, in Figure 5, ROC curves of NSTE-ACS patients showed that NT-proBNP had higher sensitivity and specificity (cut-off $=415 \mathrm{pg} / \mathrm{mL}, 92 \%, 39 \%$, respectively), followed by Tn-T (cut-off $=0.045 \mathrm{ng} / \mathrm{mL}$ ) and CK-MB, (cut-off $=5.7 \mathrm{IU} / \mathrm{L})$, for both $(84 \%, 6 \%$, respectively) as shown in Table 3. The area under the curves was 0.68 , $0.31,0.17$, for NT-proBNP, Tn-T, CK-MB, respectively. In Figure 5, NT-proBNP had clinical significance, $p=$ 0.02 , at $95 \%$ confidence interval, the lower bound $=0.52$ and the upper bound $=0.82)$. There was a correlation between Tn-T and CK-MB $(r=0.3, p=0.01)$ and inverse correlation between NT-BNP and CK-MB $(r=$ $-0.2, p=0.03)$, positive correlation between smoking and dyslipidymia $(r=0.4, p=0.01)$, inverse correlation between number of vessels affected and smoking $(r=$ $-0.34, p=0.01)$. There was no significant difference in the LVEF determined by echocardiography between NSTE-ACS patients $(57.1 \% \pm 9.8 \%)$ and STE-ACS patients $(56.6 \% \pm 10.9 \%)$ because we excluded patients with pump failure ( $\geq$ Killip class II). NT-proBNP increased in NSTE-ACS patients in the early phase of ACS

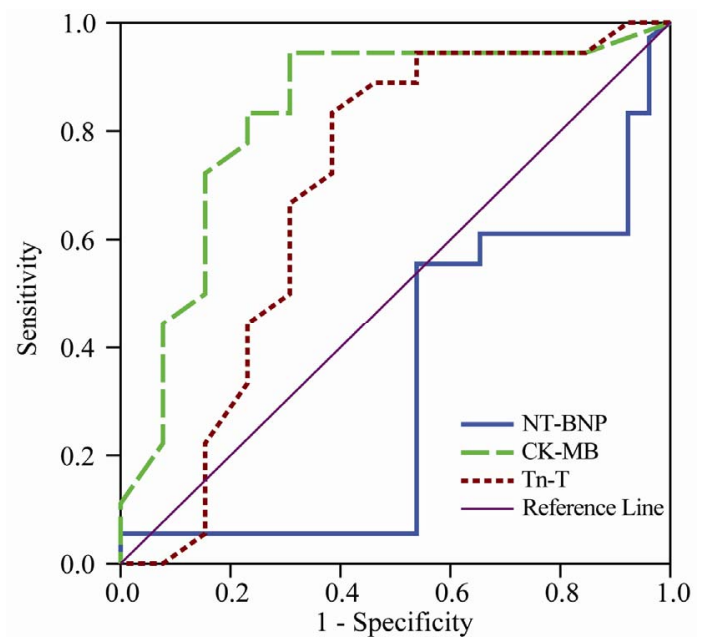

Figure 4. ROC Curve in STE-ACS.

Table 2. Comparison of cardiac markers in all patients (62) with ACS by ANOVA test.

\begin{tabular}{|c|c|c|c|c|c|c|c|c|}
\hline & \multirow{2}{*}{ Mean $\pm \mathrm{SE}$} & \multirow{2}{*}{$p$} & \multirow{2}{*}{ Minimum } & \multirow{2}{*}{ Maximum } & \multirow{2}{*}{$\begin{array}{c}\text { Mode } \\
\text { (frequency) }\end{array}$} & \multicolumn{3}{|c|}{ percentiles } \\
\hline & & & & & & 25 th & $50^{\text {th }}$ (median) & 75th \\
\hline NT-proBNP (pg/mL) & $1124.35 \pm 103.9$ & 0.001 & 200 & 2800 & $\begin{array}{c}2400 \\
(10)\end{array}$ & 380 & 680 & 2000 \\
\hline CK-MB (IU/L) & $10.75 \pm 0.6$ & 0.000 & 5.60 & 19.20 & $\begin{array}{c}5.6,18 \\
(6)\end{array}$ & 6.1 & 9.2 & 15 \\
\hline Tn-T (ng/mL) & $0.41 \pm 0.02$ & 0.002 & 0.01 & 0.80 & $\begin{array}{l}0.6 \\
(6)\end{array}$ & 0.32 & 0.45 & 0.6 \\
\hline
\end{tabular}


Table 3. Sensitivity and specificity of cardiac markers.

\begin{tabular}{lcc}
\hline & \multicolumn{2}{c}{ STE-ACS } \\
\cline { 2 - 3 } & Sensitivity & specificity \\
\hline $\begin{array}{l}\text { NT-proBNP } \\
\text { cut-off }=415 \mathrm{pg} / \mathrm{mL}\end{array}$ & $61 \%$ & $8 \%$ \\
$\begin{array}{l}\text { CK-MB } \\
\text { cut-off }=5.7 \mathrm{IU} / \mathrm{L}\end{array}$ & $94 \%$ & $6 \%$ \\
$\begin{array}{l}\text { Tn-T } \\
\text { cut-off }=0.045 \mathrm{ng} / \mathrm{mL}\end{array}$ & $94 \%$ & $6 \%$ \\
$\begin{array}{l}\text { NT-proBNP } \\
\text { cut-off }=415 \mathrm{pg} / \mathrm{mL}\end{array}$ & $92 \%$ & NSTE-ACS \\
$\begin{array}{l}\text { CK-MB } \\
\text { cut-off }=5.7 \mathrm{IU} / \mathrm{L}\end{array}$ & $84 \%$ & $39 \%$ \\
$\begin{array}{l}\text { Tn-T } \\
\text { cut-off }=0.045 \mathrm{ng} / \mathrm{mL}\end{array}$ & $84 \%$ & $6 \%$ \\
\hline
\end{tabular}

and it was inversely proportional to the duration of chest pain. It was more significant increased when the duration of chest pain was $\leq 4$ hours than $\leq 6$ or $\leq 8$ hours as shown Figures 6-8 respectively.

\section{Discussion}

Cardiac markers, such as troponin $\mathrm{T}(\mathrm{TnT})$, and creatine kinase (CK)-MB isozyme, detect the development of minor myocardial necrosis, and have emerged as powerful predictors of risk in patients with ACS $[11,12]$. Pro-BNP was synthesized as a pro-hormone by cardiac myocytes then cleaved by enzyme to N-teminal proBNP (NT-proBNP) and BNP. NT-proBNP levels predicted long term survival in patients. The highest NT pro-BNP quartile was twice as likely to die when compared to patients with left ventricular hypertrophy in the lowest NT-ptoBNP quartile [7].

In this study, Nt-proBNP was significantly higher in NSTE-ACS patients than in STE-ACS patients despite lower values of the conventional cardiac markers CK-MB and Tn-T in NSTE-ACS patients. The increment of NT-proBNP in NSTE-ACS patients was inversely proportional to the duration of chest pain. It was more significant increased when the duration of chest pain was $\leq 4$ hours than $\leq 6$ or $\leq 8$ hours. It increased during the hyperacute phase in NSTE-ACS patients, and wasn't raised by the process of myocardial necrosis but the ischemic insult per se. This may be explained on the basis that the release kinetics of cardiac markers, especially NT-proBNP, in patients with NSTE-ACS differed from those in STE-ACS patients. The ischemic area or area at risk showed different spectrum in these 2 groups. The massive elevations of NT-pro-BNP observed in the early phase of coronary syndrome seemed to be independent of ventricular performance. Also, STEMI was caused by acute total coronary occlusion, whereas NSTEMI was associated with vulnerable plaque and

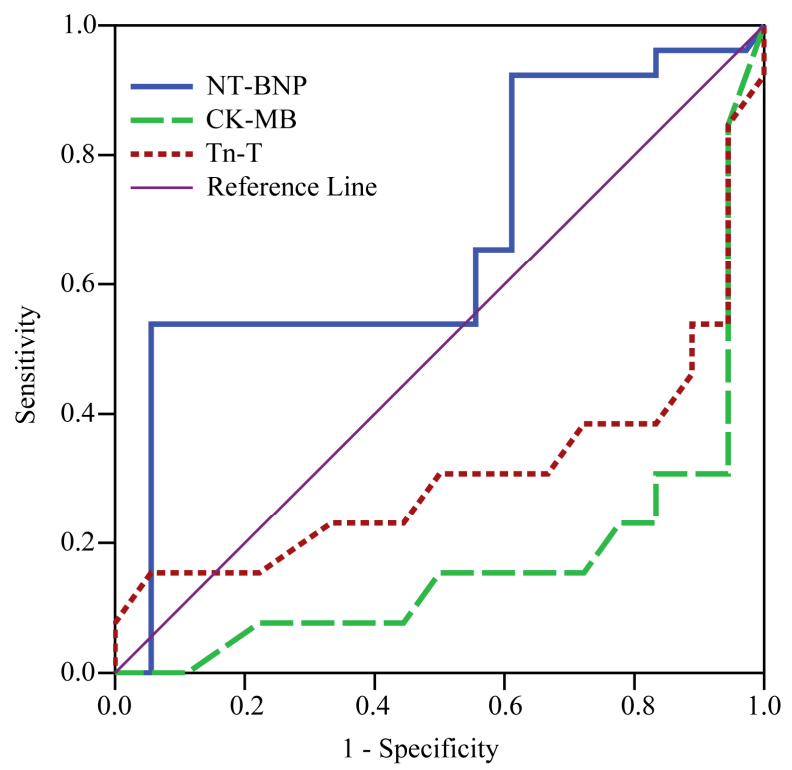

Figure 5. ROC Curve in NSTE-ACS.

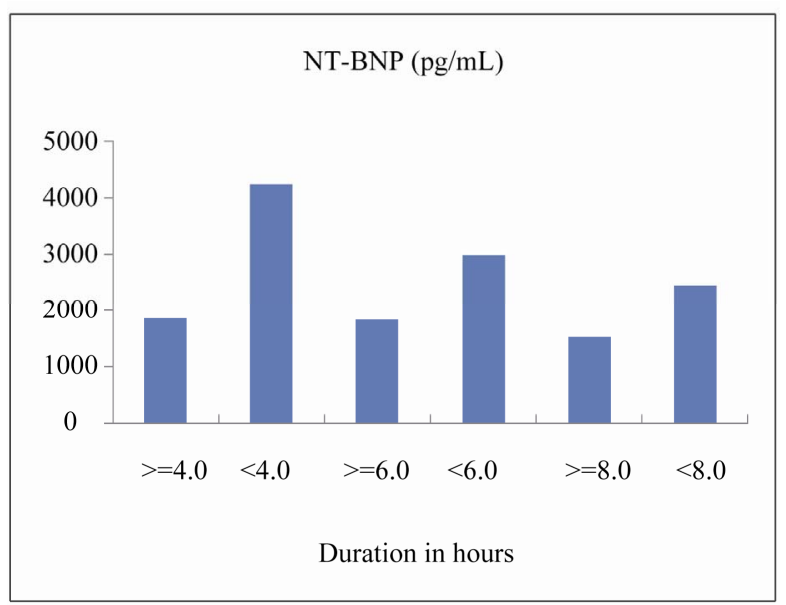

Figure 6. NT-proBNP in all patients with ACS.

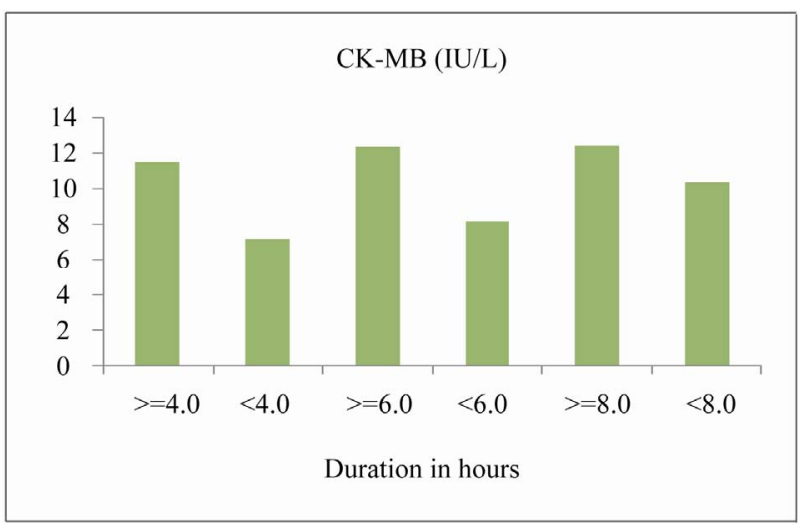

Figure 7. CK-MB in in all patients with ACS. 


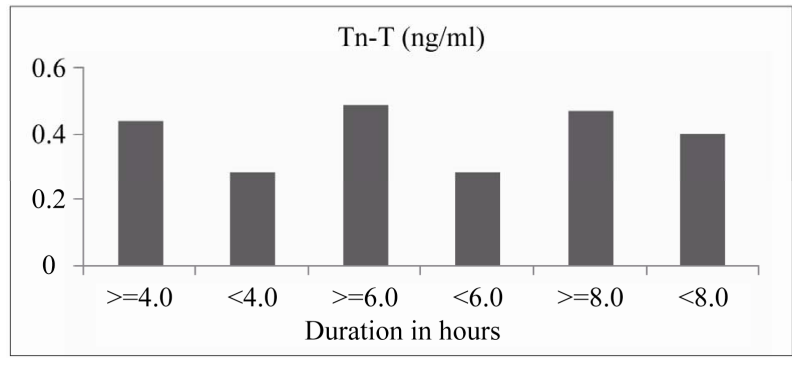

Figure 8. Tn-T in all patients with ACS.

subocclusive thrombosis [8]. The myocardial ischemia was also a stimulus for the release of $\mathrm{BNP}$ and NT-proBNP $[13,14]$. The underlying pathomechanism was not fully understood, but a direct release of BNP from ischemic cardiomyocytes in addition to ischemia induced by increase in ventricular wall stress was postulated and, moreover, there was evidence suggested a protective role of BNP on the myocardium. BNP and other natriuretic peptides limit the extent of tissue infarction during ischaemia and reperfusion. The mechanism of cytoprotection is related to cGMP accumulation and opening of ATP-sensitive $\mathrm{K}(+)$ channels $[15,16]$. The early activation of the natriuretic peptide receptor/cGMP signalling system may be an important autocrine/paracrine response in cardiac ischaemia. This includes inotropic effects, acute regulation of coronary vascular tone and attenuation of the susceptibility of myocardium to ischaemic injury, suppression of growth and proliferative responses in a variety of myocardial and vascular cells. In ischaemic myocardium, acute treatment with BNP prior to and during coronary artery occlusion exerts a markedly protective, concentrationdependent infarct-limiting action. This cytoprotective effect of the natriuretic peptide signalling pathway might conceivably represent an alternative endogenous salvage pathway in myocardium which is potentially exploitable therapeutically. Taken together, the acute actions of natriuretic peptides on the coronary vasculature and in myocardial ischaemia suggest a profile of activity that may be therapeutically beneficial in the management of patients with acute coronary syndromes [17]. Thus may be according to our data, treatment with BNP or NT-BNP peptide within 4 hours from onset of chest pain will give best results of protection. Age stratification of NT-proBNP using cut points of 450, 900, and 1,800 $\mathrm{ng} / \mathrm{L}$ (for age groups of $<50,50-75$, and $>75$ years) reduced false-negative findings in younger patients, reduced false-positive findings in older patients, and improved the overall positive predictive value of the marker without a change in overall sensitivity or specificity [18]. In this study, the elevation of NT-proBNP was much higher in the NSTE-ACS patients than STE-
ACS patients (506 pg/mL vs 201 pg/ml). NT-pro- BNP was higher in NSTE-ACS patients than STE-ACS patients $(758 \mathrm{pg} / \mathrm{mL}$ vs $258 \mathrm{pg} / \mathrm{mL})$. Such early increased would reflect the amount of ischemic insult to the myocardium rather than the actual extent of myocardial damage or degree of heart failure [19]. A correlation between LVEF and plasma levels of BNP $(r=-0.44, p=$ 0.002) was detected [6]. However, in this study, this correlation couldn't detect because we exclude the heart failure. The use of NT-proBNP for the evaluation of the patient with suspected acute HF is useful, cost-effective, and may reduce adverse outcomes compared with standard clinical evaluation without natriuretic peptide testing [20].

In a multivariate Cox regression model, N-BNP added prognostic information above and beyond Killip class, patient age, and left ventricular ejection fraction. Adjustment for peak troponin $\mathrm{T}$ levels did not markedly alter the relation between N-BNP and mortality. In patients with no evidence of clinical heart failure, N-BNP remained a significant predictor of mortality after adjustment for age and ejection fraction. N-BNP is a powerful indicator of long-term mortality in patients with ACS and provided prognostic information above and beyond conventional risk markers [21,22].

\section{Conclusions}

NT-proBNP is an early sensitive marker of ACS as it increased significantly in the early phase of ACS (less than 8 hours), with much increment when the chest pain duration less than 4 hours. It is very sensitive and specific than other traditional cardiac markers (CK-MB and TnT) in the early diagnosis of NSTE-ACS which caused very big problem in the early diagnosis than STE-ACS.

\section{REFERENCES}

[1] Y. Seino, A. Ogawa, T .Yamashita, M. Fukushima, K. Ogata, H. Fukumoto and T. Takano, "Application of NtProbnp and Bnp Measurements in Cardiac Care: A More Discerning Marker for the Detection and Evaluation of Heart Failure," European Journal of Heart Failure, Vol. 6, No. 3, 2004, pp. 295-300. doi:10.1016/i.ejheart.2003.12.009

[2] N. Van Der Burg-de Graauw, C. M Cobbaert, C. J. Middelhoff, T. A. Bantje and C. Van Guldener, "The Additive Value of N-Terminal Pro-B-Type Natriuretic Peptide Testing at the Emergency Department in Patients with Acute Dyspnea," European Journal of Internal Medicine, Vol. 20, No. 3, 2009, pp. 301-306. doi:10.1016/j.ejim.2008.09.022

[3] P. R. Fox, M. A. Oyama, C. Reynolds, J. E. Rush, T. C. Defrancesco, B. W. Keene, C. E. Atkins, K. A. Macdonald, K. ESchober, J. D. Bonagura, R. L. Stepien, H. B. Kellihan, T. P. Nguyenba, L. B. Lehmkuhl, B. K. Lefbom, 
N. S. Moise and D. F. Hogan, "Utility of Plasma N-Terminal Pro-brain Natriuretic Peptide (NT-proBNP) to Distinguish between Congestive Heart Failure and Non- Cardiac Causes of Acute Dyspnea in Cats," Journal of Veterinary Cardiology, Vol. 11, Supplement 1, 2009, pp. S51-61.

doi:10.1016/j.jvc.2008.12.001

[4] L. Lorgis, M. Zeller, G. Dentan, P. Sicard, P. Buffet, I. L'Huillier, J. C. Beer, M. Vincent-Martin, H. Makki, P .Gambert and Y. Cottin, "RICO Survey Working Group: Prognostic Value of N-Terminal Pro-brain Natriuretic Peptide in Elderly People with Acute Myocardial Infarction: Prospective Observational Study," British Medical Journal, Vol. 6, No. 338, 2009, p. b1605.

[5] M. Heringlake, T. Kox, J. Poeling, S. Klaus, T. Hanke, N. Franz, F. Eberhardt, H. Heinze, F. P. Armbruster and L. Bahlmann, "The Effects of Physical Exercise on Plasma Levels of Relaxin, NT-proANP, and NT-proBNP in Patients with Ischemic Heart Disease," European Journal of Medical Research, Vol. 14, No. 3, 2009, pp. 106-112.

[6] O. Bruder, C. Jensen, M. Jochims, M. Farazandeh, J. Barkhausen, T. Schlosser, G. V. Sabin and P. Hunold, "Relation of B-Type Natriuretic Peptide (BNP) and Infarct Size as Assessed by Contrast-Enhanced MRI," Internal Journal of Cardiology, Vol. 144, No. 1, 2009, pp. 53-58.

[7] S. Garcia, M. S. Akbar, S. SAli, F. Kamdar, M. Y. Tsai and D. A. Duprez, "N-Terminal Pro-B-type Natriuretic Peptide Predicts Mortality in Patients with Left Ventricular Hypertrophy," Internal Journal of Cardiology, Vol. 143, No. 3, 2009, pp. 349-352.

doi:10.1016/j.ijcard.2009.03.070

[8] J. Alpert, K. Thygesen, E. Antman and J. P. Bassand, "Myocardial Infarction Redefined: A Consensus Document of the Joint European Society of Cardiology /American College of Cardiology Committee for the Redefinition of Myocardial Infarction," Journal of the American College of Cardiology, Vol. 36, No. 3, 2000, pp. 959-969.

[9] E. Braunwald, E. Antman, J. Beasley, R. M. Califf, M. D. Cheitlin, J. S. Hochman, R. H. Jones, D. Kereiakes, et al., "ACC/AHA Guidelines for the Management of Patients with Unstable Angina and Non-ST-Segment Elevation Myocardial Infarction: A Report of the American College of Cardiology/American Heart Association Task Force on Practice Guidelines (Committee on the Management of Patients with Unstable Angina)," Journal of the American College of Cardiology, Vol. 36, No. 3, 2000, pp. 9701062.

[10] D. Sahn, A. DeMaria, J. Kisslo, et al., "Recommendations Regarding Quantitation in M-Mode Echocardiography: Results of a Survey of Echocardiographic Measurements," Circulation, Vol. 58, No. 6, 1978, pp. 1072-1083.

[11] B. Haastrup, S. Gill, S. Kristensen, et al., "Biochemical Markers of Ischemia for the Early Identification of Acute Myocardial Infarction without St Segment Elevation," Cardiology, Vol. 94, No. 4, 2000, pp. 254-261.

[12] Y. Seino, K. Ogata, T. Takano, et al., "Use of a Whole
Blood Rapid Panel Test for Heart-Type Fatty AcidBinding Protein in Patients with Acute Chest Pain: Comparison with Rapid Troponin T and Myoglobin Tests," The American Journal of Medicine, Vol. 115, No. 3, 2003, pp. 185-190. doi:10.1016/S0002-9343(03)00325-5

[13] K. Bibbins-Domingo, M. Ansari, N. B. Schiller, B. Massie and M. A. Whooley, "B-Type Natriuretic Peptide and Ischemia in Patients with Stable Coronary Disease: Data from the Heart and Soul Study," Circulation, Vol. 108, No. 24, 2003, pp. 2987-2992. doi:10.1161/01.CIR.0000103681.04726.9C

[14] M. Weber, T. Dill, R. Arnold, M. Rau, O. Ekinci, K. D. Müller, A. Berkovitsch, V. Mitrovic and C. Hamm, "N-Terminal B-Type Natriuretic Peptide Predicts Extent of Coronary Artery Disease and Ischemia in Patients with Stable Angina Pectoris," American Heart Journal, Vol. 148, No. 4, 2004, pp. 612-620. doi:10.1016/j.ahj.2004.04.021

[15] J. Goetze, C. Christoffersen, M. Perko, H. Arendrup, J. F. Rehfeld, J. Kastrup and L. B. Nielsen, "Increased Cardiac BNP Expression Associated with Myocardial Ischemia," The Journal of the Federation of American Societies for Experimental Biology, Vol. 17, No. 9, 2003, pp. 1105-1107.

[16] G. F. Baxter, "Natriuretic Peptides and Myocardial Ischaemia," Basic Research in Cardiology, Vol. 99, No. 2, 2004, pp. 90-93. doi:10.1007/s00395-004-0458-7

[17] Y. Rautureau and G. F. Baxter, "Acute Actions of Natriuretic Peptides in Coronary Vasculature and Ischaemic Myocardium," Current Pharmaceutical Design, Vol. 10, No. 20, 2004, pp. 2477-2482. doi:10.2174/1381612043383854

[18] J. Januzzi, A. Chen-Tournoux and G. Moe, "Amino-Terminal Pro-B-Type Natriuretic Peptide Testing for the Diagnosis or Exclusion of Heart Failure in Patients with Acute Symptoms," The American Journal of Cardiology, Vol. 101, No. 3, 2008, pp. 29A-38A. doi:10.1016/j.amjcard.2007.11.017

[19] A. Ogawa, Y. Seino, T. Yamashita, K. Ogata and T. Takano, "Difference in Elevation of N-Terminal Pro-BNP and Conventional Cardiac Markers between Patients with ST Elevation vs. Non-ST Elevation Acute Coronary Syndrome," Circulation Journal, Vol. 70, No. 11, 2006, pp. 1372-1378. doi:10.1253/circj.70.1372

[20] A. Tuğcu, O. Y1ldırımtürk and S. Aytekin, "The Diagnostic Value of N-Terminal B-Type Natriuretic Peptide in Diastolic Heart Failure: Comparison with EchocardioGraphic Findings," Turk Kardiyoloji Dernegi Arsivi, Vol. 37, No. 2, 2009, pp. 112-121.

[21] T. Omland, J. De Lemos, D. Morrow, et al., "Prognostic Value of N-Terminal Pro-atrial and Pro-brain Natriuretic Peptide in Patients with Acute Coronary Syndromes," American Journal of Cardiology, Vol. 89, No. 4, 2002, pp. 463-465. doi:10.1016/S0002-9149(01)02271-8

[22] T. Omland, A. Persson, L. Ng, et al., "N-Terminal Pro-B-Type Natriuretic Peptide and Long-Term Mortality in Acute Coronary Syndromes," Circulation, Vol. 106, 2002, pp. 2913-2918. 